\title{
Representatives and advertisements as sources of information
}

\author{
A. E. Holland \\ B.Sc., A.M.B.I.M., M.Inst.M.
}

Lederle Laboratories

\begin{abstract}
Summary
The role of the representative and advertisements as information sources is discussed. Emphasis is placed on these as providing only part of the whole data package available to a doctor to enable him to make his prescribing decision.
\end{abstract}

THIS brief presentation is not intended to be a distillation of the general opinion and beliefs held by the author's colleagues and competitors in the pharmaceutical industry, but rather his own personal views on the subject under discussion. He can speak, however, from first-hand experience of present day ethical advertising and deployment of medical representatives backed by a great number of years of experience within the pharmaceutical industry.

In session I, Dr Dingwall and Dr Hunter gave their views on the information needs of the general practitioner and hospital prescribers before they will actually commit their decisions on a prescription form. All can appreciate that their decisionmaking process is vital: the author feels that the onus of making the correct diagnostic decision is even more important than that of prescription decision. The author quotes from a recent study on how general practitioners assess risks in using new drugs, "he is required daily to make decisions about diagnosis and treatment in which there will normally be uncertainty and which often promise devasting consequences should a wrong decision be made'.

In the matter of obtaining or being provided with information the author believes that all are guilty of deluding themselves by assuming that what they have obtained is information when in fact all they have are data. At some time or other, most have heard the familiar statement 'I am sorry, we seem to have plenty of data on file but unfortunately not much information'. The essential point here is the way in which those data have to be interpreted, evaluated and validated by each one individually to suit his own requirements, and thus render the conclusions he makes understandable and usable pieces of information. A medical audience sometimes voices its opinions verbally, or in the Press, say that it is bombarded with information and apparently assailed by medical representatives. Yet by far the largest proportion of general practitioners readily admit that they rely upon the medical representative as one of their most important sources of information.

In 1966, the Sainsbury Report declared that representatives were the prime source of information on new products. In 1975 just under 400 general practitioners were asked to indicate which one of the media had been most important to them for obtaining information on new products; once again they gave representatives the number one rank. In the same survey $60 \%$ of doctors agreed that representatives provide the most effective two-way communication between the doctor and the industry.

The business objective of the pharmaceutical industry is not to sell drugs. This is analogous to the definition that film companies are not in business to make films - they are in the business of entertainment and education. Similarly the business of the ethical pharmaceutical industry is not just making or selling drugs - the business is human health and welfare. It is therefore in the interests of the industry, both as potential patients as well as employees, to ensure that the information provided is balanced, credible and factual.

Next is the subject of advertisements those open, persuaders which smother every medical journal available to the medical profession.

The advertisements of the Lederle Laboratories, or the information disseminated by their representatives, are intended to create in the doctor's mind the right environment within which he can decide which anti-inflammatory antibiotic or beta-blocker he should prescribe. It is freely admitted that it would obviously be desirable for him to prescribe a Lederle product, but the Laboratories' representative is well aware of and respects the fact that it is the doctor's own ultimate decision which is final. It is also appreciated that the competititive situation whereby his opposite numbers in other companies are endeavouring to do just the same for their antiinflammatory, antibiotic or beta-blocker.

The ABPI Code of Pactice defines two sorts of journal advertisement, one, where the purpose of the printed promotional material is to provide the medical profession with sufficient information upon 
which to reach a decision for prescribing or for use, and two, where the purpose of the printed promotional material is to remind recipients of the availability and of the main indication of a product. At the level of the advertising executive where the advertisements are designed and the objectives decided, he maintains that his real intention is to inform his target audience of a fact or a simple message, but only as a part of his overall compaign which would also involve medical representation, meetings, symposia and the like. However, he concurs with the requirement that every advertisement should state the approved or other non-proprietary names of the active ingredients, the brand name of the product, and the company's name and address, but the author thinks it is a little naive of anybody to consider that any doctor reading an advertisement in a journal or a piece of literature sent through the post, or handed to him by a representative is going to allow that to be the only item upon which he is going to make a decision for prescribing. The next part of the subject under discussion considers representatives as a source of information.

Throughout the length and breadth of the country those who are intimately involved with the pharmaceutical industry are aware of basic statistics such as 25,000 general medical practitioners under the age of 65 , approximately 34,000 hospital medical practitioners either full-time or part-time within the NHS, roughly 14,000 pharmacies and 150 pharmaceutical companies ranging from vast multi-nationals with wide product ranges to small companies who may have only one or two products at the most. These companies overall employ some 3000 medical representatives whose primary function is to communicate to doctors and pharmacists the medical information which is required for prescribing purposes, or to assist them in handling the speciality products which can only be used under their care and supervision. No doubt in the past and perhaps even in today's more enlightened environment it is possible that there are companies who employ representatives who have very little background or training, or even the ability to communicate medical information. However, by far the greatest majority of medical representatives are carefully selected for the job they are required to undertake, and trained in more than just selling and knowledge of products.

They are also trained in the necessary background skills which they require effectively to direct the information which they have been given to impart to the chosen audience in such a way that both the recipient and the representative clearly understand the significance of the message. The author's own personal experience of medical representatives is based upon involvement with three major pharmaceutical houses but he has no reason to suppose that his observations of medical representatives are any 3

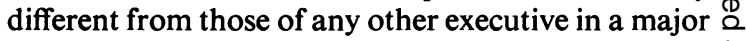
pharmaceutical company.

He sometimes gets the impression that politicians $\overrightarrow{\vec{A}}$ and National Health Service administrative staff $\stackrel{+}{\rightarrow}$ believe that pharmaceutical companies from time to time open their front doors and take in the first ten to fifty passers-by whom they then train for anything from a few days to several months, give them a $\triangle$ company car and an expense account and then send क them out to see their first prospective client with a $\overrightarrow{0}$ view to ensuring that the doctor 'prescribes our products, and prescribes twice as much as the $\vec{\omega}$ national average per patient'. It is believed that this kind of image has given rise to officialdom's mistrust of the personal integrity, and abilities and dedication of such people to present information to doctors in an informative and unbiased manner.

The industry selects for its representatives people from all walks of life although obvious preference 0 is given to those with a scientific background and education, but this is not the only criterion of the selection process. This is not the time to go into the $\vec{c}$ personal attributes which are required of a medical $\frac{\mathbb{O}}{8}$ representative, but let it only be said that if the majority of medical representatives are technically $\bar{Z}$ inadequate then one would not be able to obtaip $\stackrel{\Phi}{-}$ unsolicited appreciation of representatives frop $\overrightarrow{0}$ people such as the doctor who selected represen. tatives as one of the major sources of information of pharmaceutical products. Some might say that given that medical representatives provide an information service, could not a better, less biased, less commerically orientated, personalized medium be provided within the structure of the National Health Service? In part, they would be right because the service provided is commercially orientated but the doctor is well aware of this and in the ultimate analysis tempers his prescribing decisions accordingly. However, what the question does not allow for is how such pure, untarnished information can be presented to the medical profession in an interesting and succinct form. One could perhaps imagine the well dressed, well educated gentleman, or lady, sitting in front of a general practitioner and saying ' $I$ am from the Ministry of Medical Information and it is my duty to explain to you the presentations, uses, $D$ dosage and administration, contraindications, the precautions, side effects, treatment of over dosage, $N$ legal categories, package quantities, NHS prices, plus compatibilities with other preparations, and the techniques of injection as required of the eightytwo products which you should consider before arriving at a prescribing decision for any of your $Q$ hypertensive patients'. Another alternative to that official type of approach to the doctor is to make available to him data banks which provide informa- 
tion on request. The establishment of libraries and information centres, however generalized or specialized their intentions may be, requires that the doctors actually know what information they need and can afford the time to visit these centres, write letters or make telephone calls.

It cannot be claimed that advertising will be or ever has been a prime source of information on prescribing. Whatever the market, for example buying domestic items for the home, or quantities of equipment for various companies, the purchasers will have to admit that each feels reassured if the product information or confirmation of detail is given verbally by the appropriate salesman. Yet it must be admitted that one can be influenced by advertisements and gain some information from them. So, advertisements and representation are rather like icing and cake. The final satisfaction comes in the eating but it certainly looks nicer and is better presented if it has some icing on the top and is presented as a complete package.

The conclusion, therefore, is that there is undoubted advantage in presenting the merits of existing products and the advantages of new developments to prescribers who are the industry's target audience. The proved and most acceptable way of presenting this kind of information is undoubtedly by verbal, two-way communication between the salesman on the one hand and the doctor on the other.

It must be accepted that standards can never stand still and the representatives will become even more professional, but the National Health Service will find it extremely difficult to be able to provide the kind of service which the industry's medical representatives provide, since, without such well trained staff it would take doctors much longer to find out about new products or product developments. By far the majority of doctors see the representatives' function as firstly introducing new products, secondly for sales promotion, thirdly providing reminders on existing products, and fourthly providing up-to-date information.

The claim is therefore made that representatives and advertising are the most important sources of medical information to the National Health Service. The author is quite confident that the pharmaceutical industry will continue to improve the quality of the information services of its representatives, to support them with increasingly sophisticated company information data banks, and to reinforce the salient facts with direct advertising. In that way the National Health Service can, therefore, at an economical price, both have its cake and eat it. 